\title{
Pelatihan Media Sosial Sebagai Media Informasi dan Publikasi Pada Organisasi Fatayat NU Ciledug Kota Tangerang
}

\author{
George W. Bender ${ }^{1}$, Ita Suryani ${ }^{2}$, Siti Qona'ah $^{3}$, Intan Leliana $^{4}$, Dinda Laela Putri ${ }^{5}$, \\ Annisa Febianti ${ }^{6}$, Putri Indrina Napitupulu ${ }^{7}$ \\ 1,2,3,4,5,6,7 Universitas Bina Sarana Informatika \\ Jalan Kramat Raya No.98 Kwitang Senen Jakarta, Indonesia \\ e-mail: ${ }^{1}$ george.gwn@bsi.ac.id, ${ }^{2}$ ita.its@bsi.ac.id, ${ }^{3}$ siti.sqa@bsi.ac.id, ${ }^{4}$ intan.ila@bsi.ac.id, \\ ${ }^{5}$ dindalaelaputri@gmail.com, ${ }^{6}$ annisafebi28@gmail.com, ${ }^{7}$ putriindrina18@gmail.com
}

\begin{abstract}
Abstrak
Perkembangan media sosial saat ini dimanfaatkan untuk berbagai macam kepentingan, yaitu menjalin hubungan pertemanan, melakukan program kampanye seperti bidang agama, sosial, pendidikan, kesehatan, lingkungan, media informasi, publikasi sampai promosi. Mitra pengabdian masyarakat ini adalah organisasi Fatayat NU Ciledug Kota Tangerang yang tergolong pada mitra yang produktif secara ekonomi/ sosial. Organisasi Fatayat NU Ciledug beranggotakan laki-laki, perempuan dan juga anak-anak. Program kegiatan yang ada pada organisasi Fatayat NU Ciledug yaitu (1) kegiatan pengajian yang rutin dilakukan setiap minggu, (2) Kegiatan Unit Kegiatan Masyarakat (UKM) kegiatan yang sangat produktif yang dapat memberikan pendapatan/peluang bagi masyarakat dalam bidang wirausaha, (3) Kegiatan Jumuah Berkah di lakukan oleh ibu - ibu majelis Fatayat NU Kecamatan Ciledug yaitu dengan membagikan makanan/minuman dan perlengkapan solat kepada yang membutuhkan. Permasalahan yang terdapat pada mitra yakni belum maksimalnya pengelolaan media sosial sebagai media informasi dan publikasi serta belum maksimalnya SDM yang mengelola media sosial Fatayat NU Ciledug Kota Tangerang sehingga hal tersebut menjadi salah satu kendala. Solusi yang diberikan yaitu melalui pendampingan dan pengelolaan terkait pengembangan media sosial melalui hal-hal : a. bagaimana cara melakukan pengembangan media sosial yang mumpuni sesuai dengan kebutuhan informasi, $b$. bagaimana pengelola media sosial agar menjadi media informasi dan publikasi yang tepat sasaran dan sesuai tujuan c. Bagaimana menjaga isi dan tampilan media sosial agar menarik.
\end{abstract}

\section{Kata Kunci: Media Sosial, Media Informasi, Publikasi}

\begin{abstract}
In its development, social media is used for various purposes, starting from making friends, certain program campaigns (education, social, religion, environment, health, etc.), information media, publications to promotions. This community service partner is the Fatayat NU Ciledug organization Tangerang City which is classified as an economically/socially productive partner. The Fatayat NU Ciledug organization consists of men, women and children. The program activities that exist in the Fatayat NU Ciledug organization are (1) recitation activities that are routinely carried out every week, (2) Community Activity Unit (UKM) activities are very productive activities that can provide income/opportunities for the community in the field of entrepreneurship, (3) The Jumuah Berkah activity was carried out by the women of the Fatayat NU assembly, Ciledug District, namely by distributing food/drinks and prayer equipment to those in need. The problems found in partners are that
\end{abstract}

This work is licensed under a Creative Commons Attribution-ShareAlike 4.0 International License.

Publikasi oleh LPPM Universitas Bina Sarana Informatika 
the management of social media as a medium of information and publications is not maximized and the human resources that manage Fatayat NU Ciledug social media are not optimal, Tangerang City, so that this is one of the obstacles. The solution in this community service is by providing assistance and management related to the development of social media through the following: a. how to develop qualified social media according to information needs, $b$. how to manage social media so that it becomes a media of information and publications that are right on target and in accordance with the objectives $c$. How to keep the content and appearance of social media attractive.

\section{Keywords: Social Media, Information Media, Publications}

\section{Pendahuluan}

Belum maksimalnya pengelolaan media sosial sebagai media informasi dan publikasi serta belum maksimalnya SDM yang mengelola media sosial Fatayat NU Ciledug Kota Tangerang tersebut menjadi salah satu kendala. Sebagai bentuk upaya yang dilakukan oleh dosen-dosen dalam mengatasi permasalahan yang ada pada Mitra Organisasi Fatayat NU Ciledug yaitu dengan mengadakan program Pengabdian Masyarakat (PM) berupa pelatihan Media Sosial Sebagai Media Informasi dan Publikasi. Program Pengabdian Kepada Masyarakat ini dilaksanakan di Organisasi Fatayat NU berlokasi di Jl. Dr. Cipto Mangunkusumo Gg Mekar Jaya RT 03/ RW 010 Kelurahan Paninggilan Utara, Kecamatan Ciledug, Kota Tangerang, dengan komposisi laki-laki sebanyak 50\% dan perempuan juga sebesar 50\% yang mana dari keseluruhan komposisi ini didominasi oleh anak-anak.

Organisasi Fatayat NU Ciledug merupakan mitra program pengabdian masyarakat yang tergolong pada mitra yang produktif secara ekonomi/ sosial.

Berikut ini adalah kegiatan yang dilakukan di dalam Fatayat NU Ciledug:

1. Kegiatan Pengajian dilakukan secara rutin di setiap minggunya. Para ustadz dan ustadzah melakukan pengajaran, pengawasan, dan evaluasi dalam kegiatan ini:

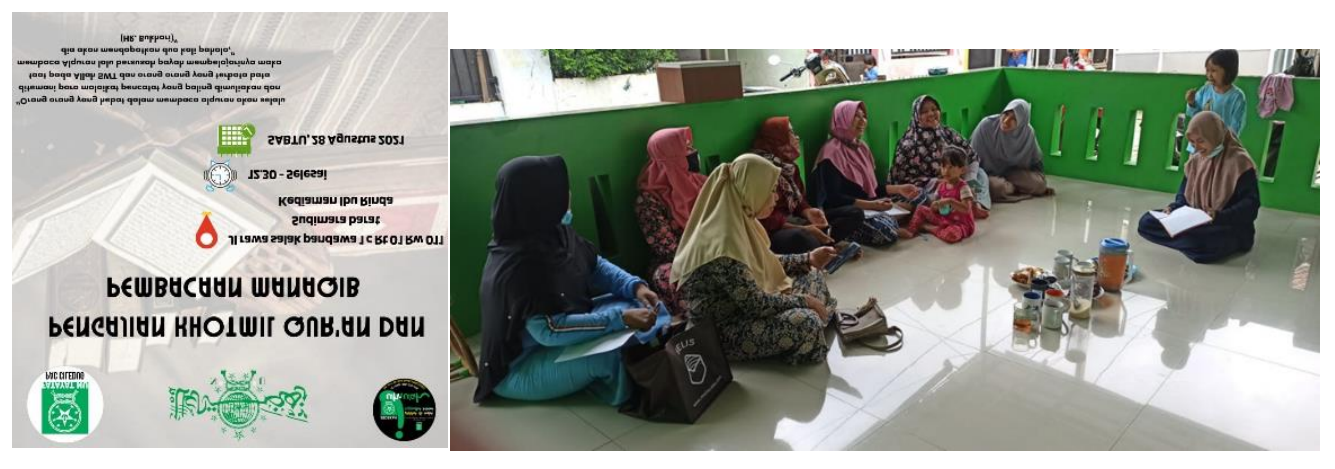

Gambar 1. Kegiatan pengajian rutin mingguan

2. Kegiatan Unit Kegiatan Masyarakat yang di lakukan oleh ibu-ibu Fatayat NU kecamatan Ciledug sangat produktif dikalangan masyarakat sekitar yang dimana bisa menghasilkan sesuatu di saat pandemi seperti saat ini, potensi peluang sangatlah besar dan sangat menguntungkan. 

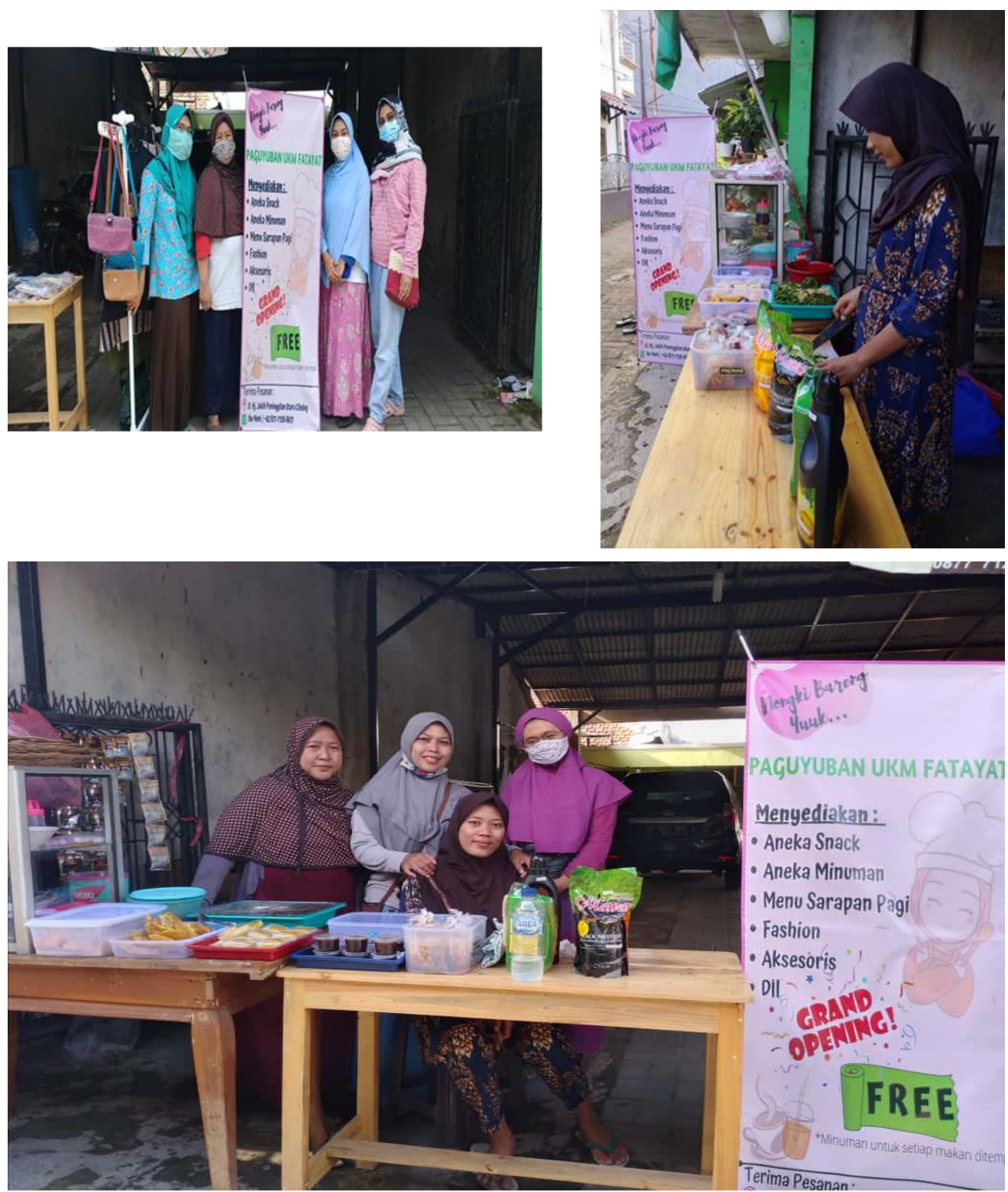

Gambar 2. Kegiatan Bazar UKM Weekend

3. Kegiatan Jumuah Berkah sangat rutin di lakukan oleh ibu - ibu majelis Fatayat NU Kecamatan Ciledug yaitu dengan membagikan makanan/minuman dan perlengkapan solat kepada yang membutuhkan. 

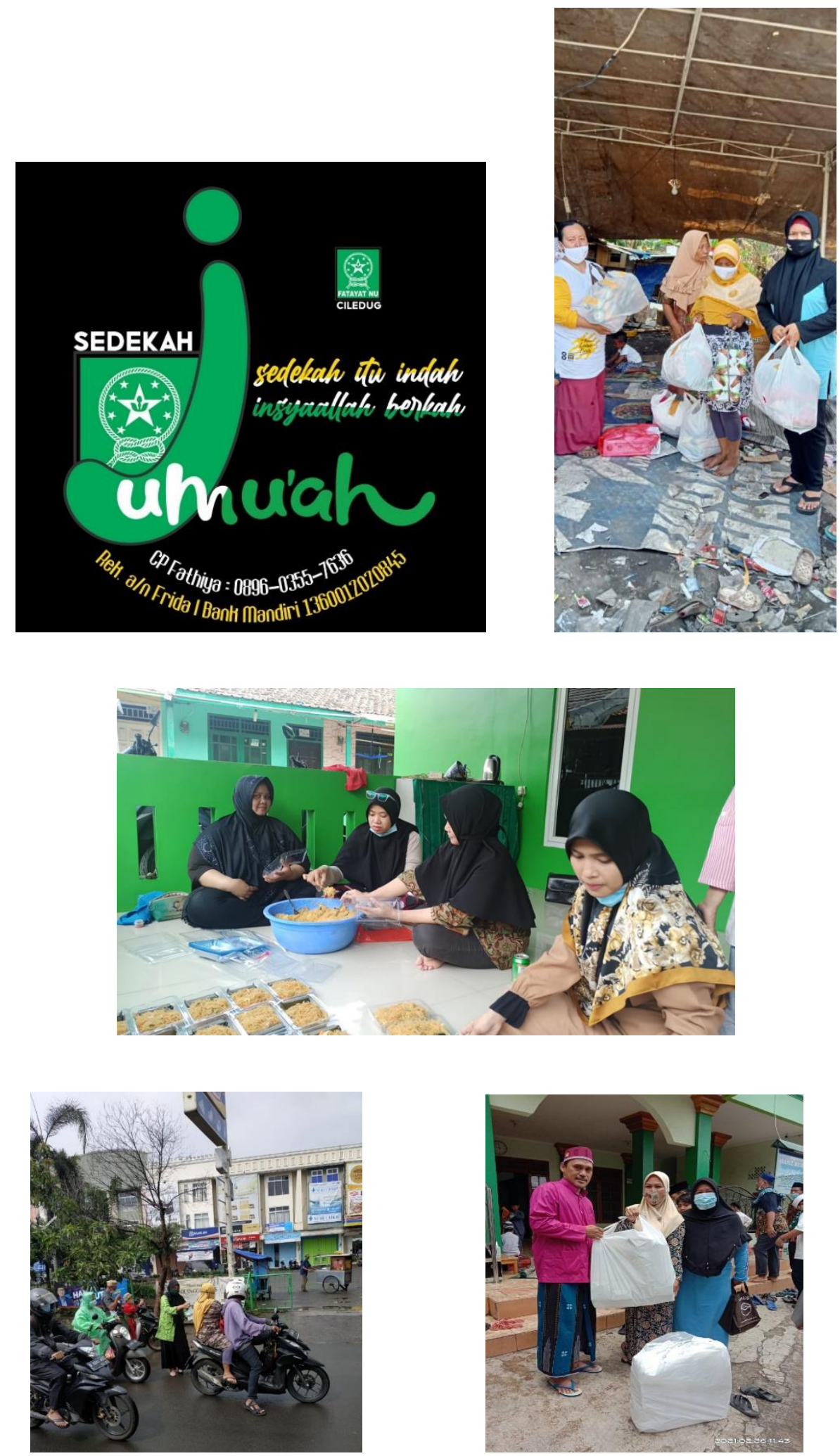

Gambar 3. Kegiatan Jumuah Berkah "pembagian makanan dan perlengkapan solat" 
4. Kegiatan mengaji dan menanamkan nilai-nilai agama dan tentunya akan menambah ilmu dan keyakinan bagi anak-anak. Aktivitas atau kegiatan dilakukan oleh anak-anak yang dibimbing oleh para ibu - ibu pengurus Fatayat NU Ciledug.
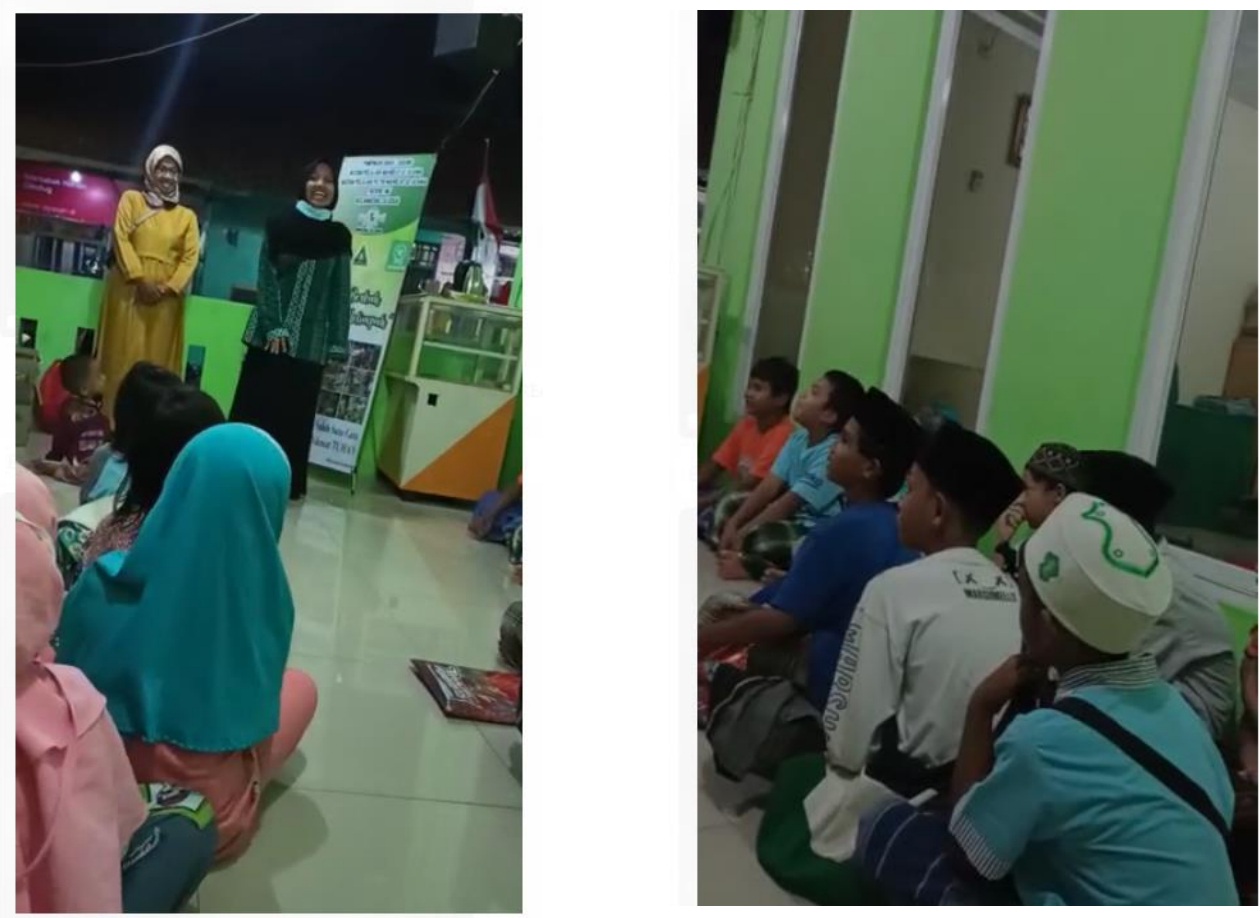

Gambar 4. Anak-anak yang sedang mengaji dan dibimbing oleh Pengurus Fatayat NU Ciledug

Fatayat NU Ciledug terus berusaha untuk mendapatkan dukungan dari masyarakat terkait eksistensinya, sehingga kegiatan/program yang dilakukan dapat memberikan dampak positif terhadap para pengurusnya maupun kepada anak-anak pengajian dan juga kepada masyarakat pada umumnya. Hal tersebut sejatinya merupakan kegiatan PR yang pada era cyber ini dapat dilakukan dengan memanfaatkan kemajuan teknologi (Saputra, 2011).

Media informasi yang efektif dalam penyampaian dan penyebarluasan informasi adalah media sosial (Noegroho, 2014). Penggunaan media sosial sifatnya lebih fleksibel, cakupannya luas, lebih cepat, efektif, interaktif, efisien dan bervariatif (Suryani, 2014). Keunggulankeunggulan tersebut menjadikan media sosial menjadi salah satu andalan dalam kegiatan digital PR (Lein, 2011).

Dalam rangka mendapatkan dukungan dari masyarakat, maka akan perlu dilakukan pelatihan sistem informasi berbasis sosial media yang akan digunakan sebagai media publikasi dan informasi kepada masyarakat mengenai keberadaan Fatayat NU Ciledug dan juga perlunya dilakukan pendampingan pengelolaan media sosial dalam rangka digital PR (Memos, 2017) terhadap pimpinan dan para pengurus Fatayat NU Ciledug melalui kerjasama dalam Program Pengabdian Masyarakat (PM) ini. Kegiatan pelatihan, pendampingan dan pengelolaan terkait pengembangan media sosial sebagai media informasi dan publikasi melalui hal-hal : a. bagaimana cara melakukan pengembangan media sosial yang mumpuni sesuai dengan 
kebutuhan informasi, b. bagaimana pengelola media sosial agar menjadi media informasi dan publikasi yang tepat sasaran dan sesuai tujuan c. Bagaimana menjaga isi dan tampilan media sosial agar menarik.

Dengan adanya pelatihan dan pendampingan ini diharapkan bagi para pengurus organisasi Fatayat NU Ciledug mendapatkan pengetahuan, menambah kemampuan (skill) dalam pengembangan media sosial serta mempermudah masyarakat untuk mendapatkan informasi mengenai profil, kegiatan/program yang ada pada organisasi Fatayat NU Ciledug.

\section{Metode}

Dalam menyelesaikan permasalahan pada organisasi Fatayat NU Ciledug metode pelaksanaan yang digunakan yaitu :

1. Tahap persiapan

Pada persiapan, mengajukan permohonan ijin untuk melakukan kegiatan pelatihan pada organisasi Fatayat NU Ciledug dan untuk mengetahui permasalahan yang dihadapi oleh mitra. Selanjutnya mempersiapkan materi pelatihan mengenai media sosial, membuat dan menyiapkan kuesioner dan soal test untuk mengetahui respon dari peserta pelatihan.

2. Tahap pelaksanaan

Tahap 1

Pada tahap ini, dimulai dengan pelatihan dan pendampingan dalam memberikan penyuluhan mengenai apa itu digital PR melalui media sosial dan bagaimana pengelolaan media sosial sangat penting dalam menunjang kemajuan organisasi Fatayat NU Ciledug terutama untuk media informasi dan komunikasi mengenai kegiatan yang dilakukan oleh organisasi Fatayat NU Ciledug serta untuk mendapatkan dukungan lebih luas dari masyarakat.

Tahap 2

Pelatihan dan pendampingan penyusunan materi media sosial sangat diperlukan untuk menyebarluaskan kegiatan organisasi Fatayat NU Ciledug sehingga dapat menjangkau publik secara lebih luas dan tepat sasaran secara efektif

3. Tahap monitoring dan evaluasi.

Pada tahap ini dilakukan dengan memberikan kuesioner kepada mitra untuk mengetahui respon dari peserta dan pada saat pelatihan, memberikan soal test yang harus diisi oleh mitra untuk mengetahui kemampuan mitra setelah dilakukan pelatihan. 


\section{Hasil dan Pembahasan}

\begin{tabular}{|c|c|}
\hline Jadwal & Kegiatan \\
\hline \multicolumn{2}{|r|}{ Sesi 1} \\
\hline $08.00-08.15$ & Sambutan dari perwakilan Universitas Bina Sarana Informatika \\
\hline $08.15-08.30$ & Sambutan dari Organisasi Fatayat NU Ciledug \\
\hline \multicolumn{2}{|r|}{ Sesi 2} \\
\hline $08.30-10.00$ & Pemaparan mengenai Media Sosial \\
\hline $10.00-11.30$ & Pelatihan dan pendampingan pengelolaan media sosial \\
\hline \multicolumn{2}{|r|}{ Sesi 3} \\
\hline $11.30-11.45$ & Pengisian kuesioner sebagai evaluasi kegiatan \\
\hline $11.45-12.00$ & Penutup, pemberian souvenir dan piagam penghargaan \\
\hline
\end{tabular}

Adapun yang menjadi peserta kegiatan ini adalah para pengurus/anggota Fatayat NU Ciledug yang berjumlah 19 orang.

Hasil diskusi yang kami temukan di lapangan yaitu program/kegiatan yang dilakukan atau profil yang dimiliki oleh Fatayat NU Ciledug Kota Tangerang belum terlalu dikenal oleh masyarakat karena untuk kegiatan/ program yang mereka lakukan walau sudah dipublikasikan melalui penggunaan media sosial yaitu akun Instagram @ fatayatnu_ciledug akun Facebook Fatayat Nu Ciledug dan Tiktok fatayatnu_ciledug nampaknya belum maksimal.

Permasalahan yang dihadapi oleh mitra:

a. Kurang maksimalnya media publikasi atau informasi mengenai organisasi Fatayat NU Ciledug dalam bentuk media sosial, sehingga keberadaan ataupun informasi mengenai organisasi Fatayat NU Ciledug dirasa masih kurang luas. Hanya orang lingkungan sekitarnya yang mengetahui. Proses informasi mitra hanya mengandalkan word of mouth (dari mulut ke mulut) atau dilihat dari kegiatan mereka seperti salah satunya kegiatan Jumuah Berkah.

b. Kurangnya SDM yang mahir dalam mengelola media sosial dan masih perlu ditingkatkannya pengetahuan dalam mengelola dan pengembangan media sosial yang berkaitan dengan profil dan informasi kegiatan/program organisasi Fatayat NU Ciledug.

Dari beberapa permasalahan yang teridentifikasi dalam Program Pengabdian Masyarakat (PM) ini maka upaya dosen-dosen dalam program Pengabdian Masyarakat (PM) yang dilakukan yaitu sebagai berikut:

\begin{tabular}{|l|l|}
\hline \multicolumn{3}{|c|}{ Kegiatan } & \multicolumn{1}{|c|}{ Hasil } \\
\hline $\begin{array}{l}\text { Memberikan pelatihan media sosial untuk } \\
\text { organisasi Fatayat NU Ciledug sebagai media }\end{array}$ & Kemampuan Mitra meningkat 90\% \\
informasi dan publikasi. Menawarkan layanan & media sosial bagi organisasi Fatayat \\
informasi yang dapat menembus ruang dan & NU Ciledug kepada masyarakat luas \\
waktu. & \\
\hline
\end{tabular}




\begin{tabular}{|l|lrr|}
\hline Melakukan pendampingan dan pengelolaan terkait & Kemampuan mitra dalam hal ini \\
pengembangan media sosial sebagai media & sumber & daya & manusia \\
informasi dan publikasi melalui hal-hal : a. & (pengurus/anggota) & organisasi \\
bagaimana cara melakukan pengembangan media & Fatayat NU Ciledug meningkat 80\% \\
sosial yang mumpuni sesuai dengan kebutuhan & dalam bidang pengelolaan media \\
informasi, b. bagaimana pengelola media sosial & sosial. & \\
agar menjadi media informasi dan publikasi yang & & \\
tepat sasaran dan sesuai tujuan c. Bagaimana \\
menjaga isi dan tampilan media sosial agar \\
menarik.
\end{tabular}

Bagi organisasi Fatayat NU Ciledug, media sosial merupakan media yang sangat penting, karena di media sosial tersebut informasi tentang profil/kegiatan ditempatkan sehingga tercipta ketertarikan dari publik dalam hal ini masyarakat terhadap program/kegiatan/profil yang ada pada organisasi tersebut.

Media sosial dapat berfungsi sebagai media engagement, dalam skala yang lebih luas. Media sosial dapat menjadi media ampuh untuk smengetahui isu-isu/tren-tren tentang apa yang aat ini diperlukan oleh masyarakat. Klarifikasi yang cepat dalam menangani masalah sangat berpengaruh pada citra organisasi. Dan engagement bisa dilakukan dengan merespons secara cepat masalah yang muncul. Membangun engagement dengan publik menjadi hal yang sangat penting karena berguna untuk membangun kepercayaan, loyalitas serta mempertahankan relasi yang bertujuan untuk mendapatkan dukungan dari masyarakat terkait eksistensi organisasi Fatayat NU Ciledug, sehingga kegiatan/program yang dilakukan dapat memberikan dampak positif terhadap para pengurusnya maupun kepada anak-anak pengajian dan juga kepada masyarakat sekitar pada umumnya. .

\section{Kesimpulan}

Dalam program Pengabdian Masyarakat (PM) yang menjadi mitra adalah Fatayat NU yang berlokasi di Kecamatan Ciledug Kota Tangerang. Organisasi Fatayat NU Ciledug memiliki anggota sebagian besar terdiri dari ibu - ibu dan anak-anak. Aktivitas/ kegiatan yang dilakukan saat ini diantaranya (1) mendengarkan ceramah tentang Al Qur'an - Hadits, Aqidah - Akhlak, Fiqih, memberikan pengajaran mengenai menulis arab mengenai hadits dan doa-doa. Pembacaan Yasin oleh anak-anak yang dibimbing guru-guru atau ustadzah-ustadzah dan ustadz-ustadz. (2) pengajian rutin setiap minggunya dan (3) kegiatan UKM - Unit Kegiatan Masyarakat guna menghasilkan sesuatu produk / karya di saat pandemi seperti saat ini, potensi peluang sangatlah besar dan sangat menguntungkan.

Fatayat NU Ciledug terus berusaha untuk mendapatkan dukungan dari masyarakat terkait eksistensinya. Dengan adanya pelatihan, pendampingan dan pengelolaan media sosial yang diberikan kepada para pengurus organisasi Fatayat NU Ciledug maka para pengurus mendapatkan pengetahuan, menambah kemampuan ( $s k i l l)$ dalam pengembangan media sosial serta mempermudah masyarakat untuk mendapatkan informasi mengenai profil, kegiatan/program yang ada pada organisasi Fatayat NU Ciledug. 


\section{Daftar Pustaka}

Lein, A. K. \& M. H. (2011). User of The World, Unite! The Challenges and Opportunities Of Social Media. Bussiness Horizons.

Memos, S. (2017). Digital In 2017. Hootsuite: Global Overview.

Noegroho, A. (2014). Teknologi Komunikasi. Yogyakarta: Graha Ilmu.

Onggo, B. J. (2012). Cyber Public Relations. Jakaarta: Elex Media Komputindo.

Saputra, W. (2011). Public Relations Teori dan Praktik Public Relations di Era Cyber. Depok: Gramata Publishing.

Suryani, I. (2014). Pemanfaatan Media Sosial Sebagai Media Pemasaran Produk Dan Potensi Indonesia Dalam Upaya Mendukung Asean Community 2015. Komunikasi, 8(2), 123 138. 